\title{
INFLUENCE OF GENDER ON TOTAL SERUM CREATINE KINASE AND CREATINE KINASE-MB LEVELS OF NIGERIAN HYPERTENSIVES
}

\author{
Henry Afamuefuna Efobi ${ }^{1}$, Iya Eze Bassey ${ }^{2^{*}}$
}

\begin{abstract}
Affiliation
1. Director, Department of Chemical Pathology, University of Calabar Teaching Hospital, Calabar, Nigeria

2. Senior Lecturer, Department of Medical Laboratory Science University of Calabar
\end{abstract}

\section{ARTICLE INFO}

Received : 23 September, 2020

Accepted : 09 August, 2021

Published : 04 November, 2021

(C) Authors retain copyright and grant the journal right of first publication with the work simultaneously licensed under Creative Commons Attribution License CC - BY 4.0 that allows others to share the work with an acknowledgment of the work's authorship and initial publication in this journal.

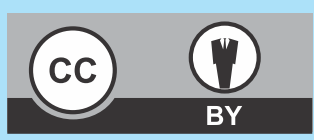

ORA 246

DOI: https://doi.org/10.3126/bjhs.v6i2.40306

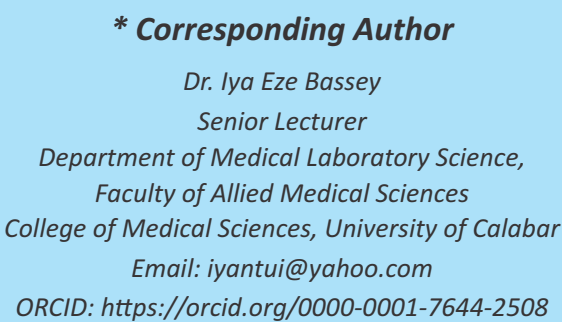

\section{Citation}

Henry Afamuefuna Efobi, Iya Eze Bassey. Influence of Gender on Total Serum Creatine Kinase and Creatine kinase-mb Levels of Nigerian Hypertensives. BJHS 2021;6(2)15. 1436-1439.

\section{ABSTRACT}

\section{Introduction}

Hypertension is a long-term medical condition which when not detected and managed properly and on time often results to complications leading to disabilities and mortality. Gender has been known to affect the interpretation of some variables necessitating the need for gender-specific ranges.

\section{Objectives}

This study evaluated total creatine kinase (CK) and creatine kinase-MB (CK-MB) isoenzyme activities of hypertensive subjects in Calabar, Nigeria and to assess if gender has influence on the activities of these enzymes.

\section{Methodology}

One hundred and two participants were consecutively enrolled in this case control study. Serum total serum CK and CK-MB activity were evaluated in fifty one hypertensive and 51 normotensive subjects. The total CK levels were assessed using a spectrophotometric method while immunoinhibition method was used to determine the activity of CK-MB. Data was analyzed using Student's t-test and Pearson's correlation. Statistical significance was set at $p<0.05$.

\section{Result}

The total creatine kinase activities of the hypertensives did not differ significantly from those of the normotensive controls ( $p=0.428$ ) while the serum CK-MB activities of the hypertensive subjects were significantly higher than those of the normotensive controls $(p=0.000)$. The body mass index of the hypertensives was significantly higher than those of the normotensive subjects $(p=0.030)$. Gender had no effect on the blood pressure, body mass index and levels of $\mathrm{CK}$ and $\mathrm{CK}-\mathrm{MB}(\mathrm{p}>0.05)$. There was also no significant correlation ( $p>0.05$ ) between blood pressure, body mass index and the levels of CK and CK-MB.

\section{Conclusion}

CK-MB activities were significantly higher in hypertensive subjects compared to normotensive controls. There were no gender specific differences in the CK-MB levels of male and female hypertensives. This cardiac marker should be included in the routine assessment of hypertensives and gender-specific considerations may not be necessary in the interpretation of the data.

\section{KEY WORDS}

Blood pressure, creatine kinase, creatine kinase $-M B$, gender, hypertension. 


\section{INTRODUCTION}

Hypertension is a chronic non-communicable disease and a major global public health problem. ${ }^{1}$ Usually defined as systolic blood pressure $\geq 140 \mathrm{mmHg}$ and/or diastolic blood pressure $\geq 90 \mathrm{mmHg}$, it accounts for up to half of both stroke and ischemic heart disease cases, and about a sixth of the total deaths globally. ${ }^{2}$ Hypertension affects about $22 \%$ of adults above 18 years, with developing nations bearing the bulk of the burden. It has been projected that by 2020, the low and middle-income countries (LMIC) will bear $80 \%$ of the cardiovascular disease burden and three quarters of all deaths in Africa may be caused by it. ${ }^{2}$ It often remains asymptomatic until late in its course. Since it has been identified as a silent killer, it is thus important to identify its risk factors and efforts made early enough to prevent its progression, attendant complications and final outcome. ${ }^{3}$

Creatine kinase is an intracellular enzyme present in cells of the heart, brain and skeletal muscle. Disruption of cell membrane of the heart due to hypoxia release creatine kinase $\mathrm{MB}$, an isoenzyme of creatine kinase, from the cellular cytosol in to the systemic circulation. ${ }^{4} \mathrm{CK}-\mathrm{MB}$ is bound lightly to the contractive apparatus and their plasma level is dependent on how severe myocardial injury is as its entry into circulation is passive. ${ }^{5}$ On this basis elevated serum level of CK-MB has been used as a sensitive marker for myocardial infarction.

Some studies have reported both racial and gender differences for CK activity in normal populations and some other diseases. ${ }^{6-8}$ It has also been documented that nonconsideration of gender-related differences could lead to the wrong classification of subjects in both epidemiological and/ or clinical studies. However, literature on gender differences in creatine kinase-MB levels among Nigerian subjects with hypertension is scarce. Therefore, this study evaluated total creatine kinase and creatine kinase-MB isoenzyme activities of hypertensive subjects in Calabar, Nigeria to assess if gender, body weight and blood pressure have influence on the activities of these enzymes.

\section{METHODOLOGY}

\section{Patients and Methods}

A total of 102 participants of Nigerian origin were consecutively recruited into this case control study. Fifty-one hypertensive patients (33 males and 18 females) were recruited from the Medical Out-patient Department of University of Calabar Teaching Hospital (UCTH) Calabar. Fifty-one apparently healthy non-hypertensive subjects (29 males and 22 females) were recruited from the environs of the Calabar metropolis. Subjects were between the ages of 40 and 65 years. This study was done in accordance with the ethical requirements of the World Medical Association. ${ }^{9}$ Ethical approval was obtained from the Cross River state ministry of Health Research ethics committee with approval number $\mathrm{CRS} / \mathrm{MH} / \mathrm{CGS} / \mathrm{BH} / 018 / \mathrm{VOLII} / 109$. The nature and purpose of the study was explained to each participant after which written informed consent was obtained. Information on the subjects' age, family history, dietary and physical lifestyle was obtained using a standard questionnaire. Blood pressure, weight and height were measured as described elsewhere. ${ }^{10}$

\section{Sample size calculation}

Power and sample size calculations for Unmatched CaseControl study were carried out using the Stat Calc function of Epi Info software (Centre for Disease control and Prevention - CDC). A two-sided confidence level of 95\%, desired Power of $80 \%$, the ratio of controls to cases as 1 and odds ratio of 3.19 from a study by Ciruzziet al., ${ }^{8}$ was utilized. The percentage outcome in the unexposed group was $55.4 \%$. The Kelsey formula 16 gave a sample size of 51 for cases and 51 for controls (i.e. a total of 102 participants).

\section{Inclusion and Exclusion Criteria}

All the subjects were known hypertensives receiving treatment for hypertension. Those with history of diabetes mellitus were excluded from this study. The controls were apparently healthy with no history of hypertension, diabetes mellitusor chronic illness and smoking. Pregnant and lactating women were also excluded.

\section{Specimen Collection}

After an overnight fast, blood samples $(5 \mathrm{mls})$ were aseptically collected from the antecubital vein into plain bottles, allowed to clot and sera extracted and frozen. The samples were thawed and used (within two hours) for total CK and CK-MB determination.

\section{Analysis of total Creatine kinase and CK-MB}

Total creatinine kinase was measured using spectrophotometric method, while immune-inhibition method was used to determine the activity of CK-MB. Both kits were obtained from Randox Laboratories Ltd, Antrim United Kingdom.

\section{Statistical Analysis}

Statistical analysis was done using the PAW statistic 18, a statistical package from SPSS Inc, California, USA. The results were expressed as Mean \pm SD. Student's t-test and Pearson's correlation was used to analyze the data. The level of significance was set at $95 \%$ confidence interval, where a probability value $(p<0.05)$ was regarded as statistically significant.

\section{RESULT}

As shown in Table 1 the mean systolic and diastolic blood pressures as well as the CK-MB activity of the hypertensive subjects were significantly higher than those of normotensives $(p=0.0001)$. However, the body mass index of the hypertensives was significantly lower than of those thenormotensive group ( $p=0.030$ ). There was no significant difference in the age and total creatine kinase of both groups.

The age, body mass index, blood pressures, total creatine kinase and creatine kinase-MB of the male hypertensives did not differ significantly from those of female hypertensives ( $p>0.05$ ) (Table2). Similar findings were observed among the male and female normotensives except for the body mass index which was significantly higher in the female normotensives. Among the normotensives: the female subjects had significantly higher BMI compare to the male subjects $(p=0.002)$. This is shown in table 3 . 
The Pearson's correlation analyses were carried out to determine the level of association between assayed variables for both the hypertensive and normotensive subjects. Table 4 and 5 contain the correlation coefficients for each of the pairing. Inspection of these tables revealed that there was no correlation between CK-MB and Body mass index; CKMB and blood pressure $(p>0.05)$

Table 1: Age, body mass index, blood pressures, total creatine kinase and creatine kinase-MB in hypertensive and normotensive subjects

\begin{tabular}{llll}
\hline Parameters & $\begin{array}{c}\text { Hypertensives } \\
\mathbf{n}=\mathbf{5 1}\end{array}$ & $\begin{array}{c}\text { Normotensives } \\
\mathbf{n}=\mathbf{5 1}\end{array}$ & $\mathbf{P}$ - Value \\
\hline Age (years) & $51.84 \pm 11.15$ & $49.82 \pm 9.60$ & 0.349 \\
BMI (kg/m ${ }^{2}$ ) & $23.95 \pm 3.80$ & $25.78 \pm 4.48$ & 0.030 \\
Systolic blood Pressure $(\mathrm{mmHg})$ & $162.21 \pm 17.51$ & $118.27 \pm 7.85$ & 0.0001 \\
Diastolic blood Pressure $(\mathrm{mmHg})$ & $101.82 \pm 10.08$ & $75.60 \pm 6.47$ & 0.0001 \\
Total Creatine kinase (IU/L) & $102.9 \pm 110.16$ & $89.79 \pm 41.21$ & 0.428 \\
Creatine kinase -MB (IU/L) & $11.97 \pm 8.1$ & $5.21 \pm 6.22$ & 0.0001 \\
\hline
\end{tabular}

Table 2: Age, body mass index, blood pressures, total creatine kinase and creatine kinase-MB in male and female hypertensive subjects

\begin{tabular}{llll}
\hline Parameters & $\begin{array}{l}\text { Male } \\
\text { Hypertensives } \\
\mathbf{n = 3 3}\end{array}$ & $\begin{array}{l}\text { Female } \\
\text { hypertensives } \\
\mathbf{n = 1 8}\end{array}$ & P - Value \\
\hline Age (years) & $52.53 \pm 12.21$ & $50.58 \pm 9.84$ & 0.549 \\
BMI (kg/m ${ }^{2}$ ) & $23.5 \pm 3.18$ & $24.72 \pm 4.20$ & 0.189 \\
Systolic blood Pressure (mmHg) & $160.8 \pm 13.1$ & $162.4 \pm 17.7$ & 0.745 \\
Diastolic blood Pressure (mmHg) & $101.6 \pm 8.6$ & $101.6 \pm 12.1$ & 0.459 \\
Total Creatine kinase (IU/L) & $116.4 \pm 126.7$ & $85.2 \pm 74.3$ & 0.284 \\
Creatine kinase -MB (IU/L) & $13.4 \pm 8.1$ & $9.6 \pm 8.0$ & 0.124 \\
\hline
\end{tabular}

Table 3: Age, body mass index, blood pressures, total creatine kinase and creatine kinase-MB in male and female hypertensive subjects

\begin{tabular}{llll}
\hline Parameters & $\begin{array}{l}\text { Male } \\
\text { Normotensives } \\
\mathbf{n = 2 9}\end{array}$ & $\begin{array}{l}\text { Female } \\
\text { Normotensives } \\
\mathbf{n = 2 2}\end{array}$ & $\mathbf{P}$ - Value \\
Age (years) & $51.14 \pm 10.65$ & $48.67 \pm 8.14$ & 0.549 \\
BMI (kg/m ( $^{2}$ & $23.94 \pm 2.51$ & $28.23 \pm 5.30$ & 0.002 \\
Systolic blood Pressure (mmHg) & $119.4 \pm 7.4$ & $118.4 \pm 6.9$ & 0.642 \\
Diastolic blood Pressure (mmHg) & $75.6 \pm 7.0$ & $75.9 \pm 6.0$ & 0.874 \\
Total Creatine kinase (IU/L) & $97.5 \pm 46.1$ & $81.8 \pm 34.1$ & 0.176 \\
Creatine kinase-MB (IU/L) & $5.9 \pm 6.6$ & $4.3 \pm 5.7$ & 0.124 \\
\hline
\end{tabular}

\section{DISCUSSION}

In this study the activities of serum Creatine kinase and its $\mathrm{MB}$ isoenzyme were evaluated in both hypertensive and normotensive subjects. Total creatine kinase activities of the hypertensive subjects did not differ significantly from that of the normotensives, though their levels were higher. It has been shown in animal models that antihypertensive therapy lowers high tissue CK in animal models. ${ }^{11}$ All the hypertensive patients in our study were on antihypertensive therapy, this may be the reason for this observation. We also observed no gender differences in the levels of total CK. This agrees with the findings of Cook et al., who reported comparable total CK activity between African males and females. ${ }^{12}$ However; it differs with the findings of other studies that have linked blood pressure with high CK activity. ${ }^{8,13-15}$ Brewster et al.,reported that there was an increase in the level of blood pressure with each log of CK activity even after adjusting for variables like age, sex, body mass index and ethnicity. ${ }^{15}$

However, the hypertensive subjects had higher CK-MB compared to the normotensive group. The severity of myocardial injury determines the plasma CKMB level. The enzyme enters the circulation by passive diffusion from infarct myocardium cells. ${ }^{5}$ Hypoxia causes a decrease in oxygen tension consequently resulting in a decrease in oxidative phosphorylation and generation of ATP. ${ }^{16}$ The drop in ATP generation affects the plasma membrane of the myocardium causing it to lose its integrity and resulting in a leaky membrane and an increase in CKMB levels. ${ }^{17}$ Even slight rises in CK-MB levels are significant prognostically. This is due to reports stating that patients with suspected infarction that had even slightly raised CK-MB levels have been linked with worse outcomes clinically. ${ }^{18}$ Our finding is in agreement with that of Emokpae and Nwagbara. ${ }^{5}$ It was observed in this study that there were no significant differences in the mean CK-MB activities between male and female hypertensivesor normotensives. Gender-related differences in CK-MB mass have been previously reported only in healthy subjects. ${ }^{19-20}$ Both studies reported that females had significantly lower levels of CK-MB mass than males among healthy subjects. They suggested that the observed differences were due to greater body muscle mass in men there by indicating a need for different gender-based decision limit values in clinical settings. However, in a study on Nigerian hypertensives, Emokpae and Nwagbara reported that serum CK-MB activity was lower in male than female hypertensives. ${ }^{5}$ Though the reason for their observation was unclear, they suggested that this may be an underlying reason for the worse clinical outcome and prognosis in women with respect to cardiovascular complications. The lack of genderspecific differences in our study implies that gender-specific considerations may not be necessary in the interpretation of the data and management of these patients.

\section{CONCLUSION}

CK-MB activities were significantly higher in hypertensive subjects compared to normotensive controls. There were no gender specific differences in the CK-MB levels of male and female hypertensives.

\section{RECOMMENDATION}

This cardiac marker should be routinely included in the evaluation of hypertensive subjects and gender-specific consideration may not be necessary in the interpretation of the data and management of these patients.

\section{LIMITATIONS OF THE STUDY}

A limitation of this study was the small size of the study population, being restricted to only one hospital.

\section{ACKNOWLEDGMENTS}

I acknowledge all the participants who agreed to take part in this study.

\section{CONFLICT OF INTEREST}

All Authors declare no conflict of interest

\section{FINANCIAL DISCLOSURE}

None 


\section{REFERENCES}

1. Laar AK, Adler AJ, Kotoh AM, Legido-Quigley H, Lange IL, Perel P, et al.,. Health system challenges to hypertension and related noncommunicable diseases prevention and treatment: perspectives from Ghanaian stakeholders. BMC Health Serv Res. 2019;19(1):693. Published 2019 Oct 15. DOI:10.1186/s12913-019-4571-6

2. World Health Organization. A global brief on hypertension: silent killer, global public health crisis. 2013. Available from https:// www.who.int/cardiovascular_diseases/publications/global_brief_ hypertension/en/

3. Kitt J, Fox R, Tucker KL, McManus RJ. New Approaches in Hypertension Management: a Review of Current and Developing Technologies and Their Potential Impact on Hypertension Care. CurrHypertens Rep. 2019;21(6):44. Published 2019 Apr 25. DOI:10.1007/s11906-019-0949-4

4. Bassey IE, Akpan UO, Nehemiah ED, Arekong R, Okonkwo OL, Udoh AE. Cardiovascular Disease Risk Factors and Cardiac Markers among Male Cement Workers in Calabar, Nigeria Journal of Chemical Health Risks. 2017; 7 (2):85-94. DOI:10.22034/jchr.2017.544169

5. Emokpae MA, Nwagbara GONA. Serum Creatine Kinase-MB Isoenzyme Activity among Subjects with Uncomplicated Essential Hypertension: Any Sex Differences. Med Sci (Basel). 2017;5(2):8. Published 2017 Apr 27. DOI:10.3390/medsci5020008

6. Neal RC, Ferdinand KC, Ycas J, Miller E. Relationship of ethnic origin, gender, and age to blood creatine kinase levels. Am J Med. 2009;122: 73-78. PMID:19114174

7. Mels CM, van Zyl C, Huisman HW. Cardiovascular function is not associated with creatine kinase activity in a black African population: The SABPA study. BMC CardiovascDisord. 2016;16:134. Published 2016 Jun 10. DOI:10.1186/s12872-016-0315-2

8. Ciruzzi M, Pramparo P, Rozlosnik J, et al. Hypertension and the risk of acute myocardial infarction in Argentina. The Argentine Factores de RiesgoCoronario en America del Sur (FRICAS) Investigators. Prev Cardiol. 2001;4(2):57-64. doi:10.1111/j.1520-037x.2001.00526.x

9. World Medical Association: Declaration of Helsinki. http:// www.wma.net/en/30publications/10policies/b3/17c.pdf

10. Akpan UO, Bassey IE. Biomarkers of metabolic syndrome in male cigarette smokers in Calabar, Southern Nigeria. N Z JMed Lab Sci. 2019; 73 (3): 111-125.

11. Jin X, Xia L, Wang LS, Shi JZ, Zheng Y, Chen WL, Zhang L, Liu ZG, Chen GQ, Fang NY. Differential protein expression in hypertrophic heart with and without hypertension in spontaneously hypertensive rats. Proteomics. 2006;6:1948-56.DOI: 10.1002/pmic.200500337. PMID: 16485256
12. Cook JC, Wong E, Haywood J. Creatine kinase: Race-gender differences in patients hospitalized for suspected myocardial infarction. J Natl Med Assoc 1990; 82:249-254. PMID: 2185368. PMCID: PMC2626127

13. Sukul S, Bahinipati J, Patra S, Ravichandran K. Serum Creatine Kinase Activity among Hypertensive Patients and its Role as a Predictor for Failure of Antihypertensive Treatment. J ClinDiagn Res. 2018;11:BC19-BC22.DOI: 10.7860/JCDR/2018/36908.12284

14. Oudman I, Kewalbansing P, Valkengoed I, Zwinderman A, Clark JF, van Montfrans GA, Brewster LM. Creatine kinase is associated with failure of hypertension treatment. J Hypertens. 2013;31:1025-1031. DOI: 10.1097/HJH.0b013e32835f5c29. PMID: 23466941

15. Brewster LM, van Bree $S$, de Visser $M$, van Montfrans GA. Hypertension in patients with idiopathic hyperCKemia. J Hypertens. 2004;22:S253.

16. Eales KL, Hollinshead KER and Tennant DA. Hypoxia and metabolic adaptation of cancer cells. Oncogenesis. 2016 Jan 25;5:e190. DOI: 10.1038/oncsis.2015.50. PMID: 26807645

17. Baird MF, Graham SM, Baker JS, Bickerstaff GF. Creatine-kinase- and exercise-related muscle damage implications for muscle performance and recovery. JNutr Metab. 2012;2012:960363. DOI: 10.1155/2012/960363. PMID: 22288008. PMCID: PMC3263635

18. Alexander JH, Sparapani RA, Mahaffey KW, Deckers JW, Newby LK, Ohman EM, et al.,. Association between minor elevations of creatine kinase-MB level and mortality in patients with acute coronary syndromes without ST-Segment elevation. PURSUIT Steering Committee. Platelet Glycoprotein IIb/IIla in Unstable Angina: Receptor Suppression Using Integrilin Therapy. JAMA. 2000;283:347 -353. DOI:10.1001/jama.283.3.347

19. Apple FS, Quist HE, Doyle PJ, Otto AP, Murakami MM. Plasma 99th Percentile reference limits for cardiac troponin and creatine kinase MB mass for use with European Society of Cardiology/American College of Cardiology Consensus Recommendations. Clin Chem. 2003;49:1331-1336. DOI:10.1373/49.8.1331. PMID: 12881449.

20. Strunz CMC, Araki LM, Nogueira AAR, Mansur AP. Gender differences in serum creatine kinase-MB mass levels in healthy Brazilian subjects. Braz J Med Biol Res. 2011; 44:236-239. DOI: 10.1590/ s0100-879x2011007500007. PMID: 21271183. 